\title{
Collegiality as a strategy for excellence in academia
}

\section{Neeta Baporikar}

Faculty of Management Sciences, Savitribai Phule Pune University, Ganeshkhind, Pune, Maharashtra 411007, India Email: neetajb@rediffmail.com

\begin{abstract}
Collegiality is a complex issue and in academia, with its culture of academic freedom and tolerance for different modes of expression, the appropriate role of collegiality raises even more questions than usual. There are at least three important aspects to collegiality in academe - the ethical imperative, the task of assessing collegiality affect on job effectiveness and the question of boundaries. Lack of collegiality can only be detrimental for the institution, turn-off students and even prompt workforce to disengage or leave altogether. Hoping things will get better is not a strategy for dealing with toxic behaviour and neither is waiting for a troublemaker to retire. Hence, ensuring collegiality is the corner stone of teaching excellence and developing academe. With in-depth observation and content analysis of secondary data, this paper aims to identify what is collegiality, role of departmental heads, and steps to nurture and develop collegiality for excellence in academia.
\end{abstract}

Keywords: academia; change collegiality; development; education; learning; management nurture; strategy; student; teacher.

Reference to this paper should be made as follows: Baporikar, N. (2015) 'Collegiality as a strategy for excellence in academia', Int. J. Strategic Change Management, Vol. 6, No. 1, pp.59-72.

Biographical notes: Neeta Baporikar, Professor (Strategic Management and Entrepreneurship) is currently on sabbatical after her academic assignment with Ministry of Higher Education, Head - Research, CAS-Salalah, Sultanate of Oman. Prior to this she was a Professor at IIIT Pune and BITS India. With more than a decade of experience in industry, consultancy and training, she made a lateral switch to research and academics in 1995. She holds DSc (Management Studies) the USA, PhD in Management, University of Pune INDIA with MBA (Distinction) and Law (Hons.). Apart from this, she is also an External Reviewer Oman Accreditation Council, Accredited Management Teacher, Qualified Trainer, Doctoral Guide and Board Member of Academics and Advisory Committee in accredited B-Schools. Reviewer for international journals, she has to her credit several refereed research papers and authored books in the area of entrepreneurship, strategy, management and higher education.

\section{Introduction}

A central theme underlying many of the current attempts to promote teacher development has been the notion that collaboration and collegiality contribute to teacher 
growth. Despite the fact that the term 'collegiality' remains somewhat problematic, as it is ill-defined, over-used and open to multiple interpretations (Darling-Hammond and McLaughlin, 1995; Hargreaves, 1993), it has come to be viewed as a critical feature of effective development efforts. Indeed, as Little (1990) has noted, collegiality advocates "have imbued it with a sense of virtue - the expectation that any interaction [emphasis added] that breaks the isolation of teachers will contribute in some fashion to the knowledge, skill, judgement, or commitment that individuals bring to their work, and will enhance the collective capacity of groups or institutions" (p.509). Although the potentially pivotal role of collegiality in teaching has been widely discussed in the literature, many questions remain unanswered: What is it about collegiality that makes it so powerful? What are the conditions under which true collegiality (as opposed to the 'contrived' collegiality described by Hargreaves (1993)) can flourish? What is the role of departmental head in promoting collegiality? What are the steps to nurture and develop collegiality? How are collaboration and collegiality related?

\section{Background}

The word 'collegiality' can be a noun, adjective or even a code word signifying potential action against someone who does not quite 'fit in'. But if your goal is to make collegiality a reality in your department or campus, then nurturing collegiality is perfect for academic administrators and faculty alike, because everyone benefits when civility reigns on campus, and everyone suffers when it does not. Because it is never easy to deal with uncivil and nasty behaviour - no matter where you are in your career - this paper based on in-depth literature review and deep observation as a departmental head would be helpful for veteran educators and administrators as well as for those who are just starting out. Collegial environments do not just happen. They have to be created and cultivated in order to thrive. Someone has to be the champion dedicated to developing and maintaining a departmental culture that is enthusiastic, collaborative and intellectual. Yes, collegiality is ultimately everyone's job, but it takes a leader to ensure that civility, and not incivility, reigns.

And that is not all. Departments that invite free expression, exploration and inquiry demand not only the right people but also the right approach. For many departments, that approach is positive academic leadership, a strategy that emphasises building on strengths and opportunities rather than simply solving problems or correcting flaws. Remember, it takes only one bad apple to spoil the basket ... and if that apple is a professor and the basket is the professorial excellence is in trouble. Incivility and lack of collegiality are on the rise in institutions of higher education (Cipriano, 2011). This phenomenon can range from disputes and tension at one end of the spectrum to violence at the other. There are many departments that suffer from non-collegial, uncivil and nasty encounters between faculty members, faculty members and professional staff, and faculty members and students.

Many of us have seen how a toxic, uncivil, non-collegial faculty member can destroy a once-great department which had professorial excellence. Such a person can create an unhealthy and poisonous environment that deleteriously affects the entire professoriate and department. Mean-spirited and uncivil people cause much damage to those they belittle, to the bystanders (students, staff and department peers) who suffer the ripple effects, to the overall academic performance, and to themselves. Faculty members who 
previously were stalwarts in the department simply disengage so that they are no longer targets to the malicious onslaught of nastiness perpetuated by this venomous person. A vicious cycle follows as faculty members retreat so they are not subject to this person's nasty attacks, students change majors because the climate in the department is contaminated, the head becomes frustrated in attempt to stop the escalating asperity and the administration is swept up in the detritus of this situation. With this background, the paper aims to identify what collegiality is and is not, construct specific procedures to create a genuinely collegial working environment and identify the troubles due to lack of collegiality. The paper also attempts to find out how to promote positive relationships, respectful encounters and suggests steps to deal with un-collegiality. This in turn should not let toxic or troubled faculty and staff stand in the way of scholarship and learning including the free flow of ideas!

\title{
3 Collegiality: a vital substance
}

Felps et al. (2006) wrote that having just one slacker or jerk in a group can bring down the team's overall performance by 30 to $40 \%$. Stanford University professor Robert Sutton (Sutton, 2007) indicates that "having just a few nasty, lazy or incompetent characters around can ruin the performance of a team or an entire organization - no matter how stellar the other employees".

People throughout all institutions of higher education have indicated that collegiality is a subjective term that could be used to 'get someone'. Collegiality, reflected in the relationships that emerge within departments, has evoked a great deal of controversy throughout higher education. Without a consistent and well-defined sense of what constitutes collegiality, many heads and deans resort to the dodge of "I recognize it when I see it", creating situations in which the likelihood of grievances, lawsuits and increased department tension is extremely high. Cipriano and Buller have developed an instrument, called the Collegiality Assessment Matrix, that reflects those observable behaviours that are regarded as most highly related to the ways in which collegiality is demonstrated in an academic setting. There is little doubt or debate that lack of collegiality is a pressing problem throughout institutions of higher education Cipriano and Riccardi (2013).

\section{Essentiality of collegiality}

\begin{abstract}
"Teaching is not something one learns to do, once and for all, and then practices, problem-free, for a lifetime ... Teaching depends on growth and development, and it is practiced in dynamic situations that are never twice the same. Wonderful teachers, young and old, will tell of fascinating insights, new understandings, and unique encounters with youngsters, the intellectual puzzle and the ethical dilemmas that provide a daily challenge. Teachers, above all, must stay alive to this." (Ayers, 1993, pp.127-128)
\end{abstract}

But today this does not seem to be so. With deep observations and in many faculty development programs it comes to light that many teachers have attributed reason to having had a non-collegial faculty member in their department. When one bad apple spoils a bunch, and one can universally identify that apple by name, there is a problem. Worse is when the way to deal with that 'bad apple' is to bury under the 
grandstands behind the football field, the problem is severe. But when there is support to productive dissent, agreeing to disagree without being disagreeable, there is a solution. Consequently, when there is clarity and candidness in our expectations of our colleagues, i.e., what is collegiality and what is not collegiality, there is a solution.

So the question for all in the academy is simple: to be part of the problem or part of the solution?

Collegiality is important to the effective functioning of an educational institution; it critically affects the performance of instructors, the coordination of curriculum within academic programs and the overall health of the institution. In cases where unpleasant and abrasive working relationships exist, productivity of individuals is affected, student learning can be negatively impacted and the curriculum may become disjointed and fractured as individuals promote different philosophies and expectations of students.

Accepting and sharing responsibility for creating a productive work setting within the department and institution result, at least to a great extent, from how well each member of the community carries his or her own fair share of the common workload. The challenges faced by higher education institutions in the 21 st century cannot be successfully mastered, nor can the efforts of dedicated professionals be sustained when the actions of a faculty member are divisive, uncompromising and inflexible. In a similar way, it is destructive to a department's morale and effectiveness when one or more of its members accept a significantly lower degree of responsibility for achieving a shared purpose. These elements lie at the heart of that salient, fundamental hallmark of successful interactions in academic life that is commonly called collegiality.

For colleagues to truly 'collaborate' and take ownership of the process of inquiry together, they need to have some shared values, goals and/or a common vision of teaching. They must have a relationship that is characterised by trust, care and mutual respect. They have to be comfortable sharing self-doubts without feeling like a failure, as well as celebrating successes without feeling arrogant. In a true collegial relationship, peers must be willing to give and receive both constructive feedback and reinforcement (McLaughlin, 1994). The time required to do these things means that there must be a serious commitment by all participants to the issue at hand. An additional challenge to those seeking to promote true collegiality, of course, is that while the formation of such relationships cannot be left to fate or happenstance, neither can they be coerced, mandated or prescribed (Deborah and Helene, 2001). One of the greatest priorities for all countries across the world is to make education more meaningful and holistic (Baporikar, 2014). The quality assurance mechanisms and suitable strategies need to be developed for strengthening the pillars of higher education (Baporikar, 2013). However, the education process continues to evolve from one-to-one (teacher to student) to collaborative learning (Baporikar, 2013), where the role of collegiality cannot be undermined.

Collegiality is reflected in the relationships that emerge within departments. It is often evidenced in the manner in which members of the department interact with and show respect to one another, work collaboratively in order to achieve a common purpose and assume equitable responsibilities for the good of the discipline as a whole. It is not an exaggeration to say that in higher education, collegiality is the cornerstone of professional work. There are many departments that suffer from non-collegial, disrespectful, uncivil and nasty encounters among faculty members, chair and faculty members, faculty members and staff, and faculty members and students. By a process of elimination, these all must be on a regular basis. Department heads are often led to believe that - this is merely the way it is - they must struggle on their own to deal with a 
non-collegial and downright nasty faculty member or it is a department culture in which civility is seriously compromised.

However, a head can take proactive steps to stem the tide of non-collegiality by recognising its telltale signs in the department:

- low morale in the department

- lack of collaboration between and among faculty members

- poor student advisement

- lack of department celebrations or social alliances

- more classes being cancelled - faculty not showing up to teach their classes

- faculty office hours not being kept

- increased absenteeism and tardiness

- diminished work quality of once-productive faculty

- new faculty struggling to survive in a hostile work environment

- older seasoned faculty worn down and becoming disengaged in department/institution

- communication within the department described as inchoate

- increased illness and health issues

- working from home more than usual or more than necessary

- increasing faculty isolation and alienation

- poor teaching evaluations from students and peers

- refusal to serve on department, school or university committees

- lack of or minimal attendance at scheduled faculty meetings.

\section{Barriers to collegiality}

Though institutions, departments and individuals generally have to work at maintaining collegial environments, yet there are obstacles in building a collegial atmosphere. The main barriers to building an inclusive team of colleagues include size of the community, geographical boundaries, personalities, habits, politics and genuine differences of opinion.

\section{What can department heads do to facilitate a collegiality in the department?}

At a department meeting, heads openly and transparently discuss:

1 What collegiality is ... and what it is not 
2 Why collegiality is important, and how non-collegial behaviour can ruin a department

3 Why the department may need a code of conduct, whereby faculty members buy into the concept that "we agree to disagree without being disagreeable"

This reflects the concept that every person pledges to treat colleagues with dignity, respect and civility and to do their fair share of the workload tantamount to running a viable department. Author Tim Gould once commented, "I've been promoted to middle management. I never thought I'd sink so low". In fact, department heads truly are the quintessential managers 'in the middle', required to balance the needs of their departments (ever-increasing in size and scope) while satisfying the desires of deans and provosts (ever-decreasing in resource allocation). In an environment of uncertainty and unpredictability, the wise head recognises that the most valuable assets in a university are its people and the intellectual capital they possess and the culture they create.

\section{Collegiality and evaluation}

Two concerns are often raised when department heads attempt to address breaches of collegiality through the evaluation process. The first is whether they are permitted to do so at all, since very few faculty handbooks list collegiality as a criterion for reviews. The second is whether evaluation is an effective means of dealing with these challenges, since collegiality is often regarded as something highly subjective and not measurable or verifiable in any consistent way. The first of these concerns can be dealt with rather quickly, while the second will require a much more extended discussion.

In the USA, courts have ruled consistently that it is appropriate to consider collegiality in personnel decisions, even when an institution's policies do not specifically list it as a criterion. See, for example, Cipriano (2011, pp.153-163). So deans and heads are at liberty to take collegiality into account whenever they regard its presence as a positive factor in a faculty member's performance or its absence as a detriment. But since it is relatively uncommon for colleges and universities to describe collegiality in their policies and procedures, the second concern can actually become more difficult. After all, how do you evaluate something that is undefined, apparently nebulous in nature, and not even referred to on most forms used as part of a faculty evaluation? However, there is always a stated or unstated criterion that considers how well the probationary faculty member works with other faculty and administrators. The courts have upheld employment decisions that cite lack of collegiality, even when collegiality is not included explicitly as a requirement for continued or renewed employment (Weeks, 1996).

Perhaps the best way of dealing with this challenge is to identify the specific behaviours that, in the professional setting where you work, may be regarded as contributing to or diminishing collegiality. In other words, it is not enough to say that a person is irritable or argumentative. People are entitled to their own personalities, even when those personalities annoy us or are far different from our own. However, people are not entitled to engage in behaviour that makes the work of your program more difficult. Everyone can be in a bad mood occasionally; they can even be in a bad mood every single day. But if their mood causes them to engage in activities that affect the quality of your program, you not only have the right, you also have the duty to address it. What you are trying to change is not the person's mood, attitude or personality itself, 
but rather specific behaviours that are resulting from that mood, attitude or personality. If you are in doubt about how to tell the difference, ask yourself the following three questions:

- What is the specific problem that I am observing?

- What are the specific actions or behaviours of the faculty member that are causing those problems?

- What are the specific steps I need the faculty member to take in order to eliminate or reduce those problems?

Let us explore how these questions might function in an actual situation.

Imagine that you are responsible for evaluating professoriate members in a program that includes Dr. X, a professor who always seems to be irritable and treats colleagues and students with contempt. You have received a lot of complaints about Dr. X, and you yourself have been on the receiving end of this faculty member's foul temper. So you decide to do something about it the next time you are evaluating Dr. X. Near the end of your written review, you include the following paragraph:

Finally, I feel that I must address the issue of your frequent irritability. It is getting to the point where I dread your presence at meetings, and a number of your colleagues have mentioned that they feel they must 'walk on eggshells' whenever you are around. If you continue in this manner, it seems unlikely that many of those in your department will vote in your favour the next time you undergo post-tenure review, and I find myself reluctant to assign you junior faculty members to mentor because your temperament is so consistently unpleasant.

You dispatch this evaluation to Dr. X, a grievance is filed against you, and you are shocked to find that the appeals committee rules that your evaluation was completely inappropriate. What you did wrong was to base your evaluation, not on any specific actions that caused a documented harm to your program, but on Dr. X's personality and how it made you and others in the department feel. Your feelings of annoyance matter neither more nor less than do Dr. X's feelings of irritability. What you have done is confuse a pet peeve with a valid indication of a faculty member's performance, and that mistake could invalidate your entire evaluation.

What you should have done instead is to focus on those three questions raised earlier.

- What is the specific problem that I am observing? Are students dropping Dr. X's courses at a significantly higher rate than those of his peers and indicating to you that the professor's behaviour is the cause? Has the advising load of other members of the department increased disproportionately because Dr. X does not believe that any student is good enough to work with him? Have committees failed to meet deadlines because they cannot obtain a quorum when they know that Dr. X is likely to attend?

- What are the specific actions or behaviours of the faculty member that are causing those problems? Do students report when they drop the class that Dr. X called their questions 'stupid' and made demeaning remarks to them? Have advisees reported that Dr. X belittled them because of the way they dressed or the books they read in their own time? Do members of Dr. X's department say that there has been a chilling effect on discussions because no one is willing to be the next person publicly ridiculed? 
- What are the specific steps I need the faculty member to take in order to eliminate or reduce those problems? Can you establish guidelines for what Dr. $\mathrm{X}$ needs to do as a result of the problems you have documented? You may need to say something like, "Look. It doesn't matter to me at all how you feel about me, your colleagues, and your students. But it does matter to me how you treat us. In order for our program to grow and receive increased funding, I need every member of the department to treat every other member with professionalism and respect. From now on, when you disagree with someone, I'll expect you to direct your objections to the issue, not the person who supports that issue. You'll treat your students like the future colleagues that some of them will develop to be, not as the objects of your scorn and humiliation. Those actions are hindering your pedagogical effectiveness".

\section{Evaluation process for continued dialogue}

In order to make the evaluation process more constructive and forward-looking, reviewers should spend more time talking about what the faculty member should do than about what he or she should not do. Even in the case of Dr. X, it is not particularly effective to end the conversation by talking only about what went wrong. But it is far easier to accentuate the positive if you have already held a unit-wide conversation about what collegiality is and come to a consensus about the type of behaviour you expect of one another (Buller, 2012a, 2012b, pp.218-219, 237-238). Of course, the danger with setting behavioural guidelines that are too specific is that passive-aggressive faculty members may attempt to use those statements against us. "Our departmental code says we have to restrict our disagreements to the issues instead of the person", someone might claim. "Show me where it says that we can't roll our eyes when we do so". In these cases, you may find it valuable to review with the faculty member what the intent of the code was and how benefits accrue from a collegial work environment. It is impossible to develop a statement of principles so comprehensive that it addresses every possible contingency, so it may be necessary at times to discuss what the principles are designed to achieve, rather than the specific phrasing of the principles themselves.

While matters of collegiality can never be addressed solely through the process of faculty evaluation, periodic reviews do provide administrators with an opportunity to deal with clear breaches of professional conduct, recommend alternative behaviours for the future and underscore the significance of treating one another with respect and mutual support. Since the fundamental mission of a program is to provide a high level of instruction, scholarship and service, it becomes difficult or impossible to achieve that goal when faculty members indulge in non-collegial behaviour. It is for that reason that unprofessional actions may appropriately be addressed as part of a faculty evaluation.

The emerging field of intellectual capital focuses on the measurement of knowledge in companies, organisations, nations and regions. Intellectual capital is integrated by three sub-constructs: human capital, relational capital and structural capital. Human capital is formed by the skills and knowledge of the company's employees. The scope of human capital is internal and resides in the mind of the employee, which makes it difficult to codify. Relational capital refers to the flows of knowledge between individuals within a network and, therefore, includes the knowledge present in the relationships established with the environment. Finally, structural capital represents the knowledge that remains behind in the company when the employees have finished their working day; in other 
words, it is that knowledge that does not depend on certain individuals or specific relationships but belongs to the company (Ordóñez de Pablos, 2012; Ordóñez de Pablos et al., 2013). This is all the more true for academic institutions and organisations of higher learning.

\section{Steps for nurturing collegiality}

Ongoing problems within a department can have profound consequences, including difficulty in recruiting and retaining faculty and students, loss of funding and even program termination. While the health of a department cannot be the responsibility of a single person, the department head plays a pivotal role in getting departments out of trouble and maintaining a healthy, positive direction to nurture collegiality (Kelly, 2012).

Based on self experience, as professor of strategy and entrepreneurship and head of research/department, at the higher institutions of learning where I have worked, I have seen and had my share of thriving to struggling departments from multiple disciplines during five years as department head. I have reviewed and worked with other departments that were considered dysfunctional - where faculty members were angry at and avoided each other and often skipped department meetings. This experience has given some useful insights into managing the vigour of academic departments. Based on this the steps suggested for nurturing collegiality are as follows.

- Set strategic goals: When faculty members become heads because it is their turn, they often come in as caretakers rather than visionary leaders, making it unlikely that the department will make significant progress. "It's very important that the head has a vision that is shared with the entire faculty. You have to prioritize and focus on a couple of things that you want to accomplish as head. That will help set you on a path". Being a visionary leader means acknowledging problems and setting specific goals and objectives in an open manner. This, in most departments, it helps to lead by team-building consensus as opposed to a dictatorial approach. Some decisions a head makes are inevitably unpopular but necessary. Having open communication about decisions helps faculty understand how the decision was made. They may not agree with the outcome, but they should feel that the process was fair.

- Establish common goals/vision: It is important to talk about vision and goals and revisit/revise them when appropriate. Faculty should get together and say, "This is what we expect of us as appropriate". That builds a team. For instance, what kind of team are we? We are a team that does exceptional education at the professional level. We all have postgraduate teaching. So that brings us together as a team. The other thing that brings us together as a team is asking, "Are we as a department changing science and practice?" Although we work in smaller units, we tend to see that everybody is trying to do something to make an impact. We do not expect giant impacts. We expect small impacts. I think that is one common thought which is very important.

- Hire right: It begins with recruiting great people who are able to work with others. If you get the right people who are happy working together and are collegial, everything else will fall into place (Sorofman, 2011). Although it may be difficult to explain to superiors, sometimes it makes sense to select a solid academic who will fit 
with the culture and contribute to the team over the superstar who is more focused on individual advancement.

- Encourage faculty contributions: "It is extremely valuable to acknowledge the participation of the faculty. Thanking them is a huge part of having a strong department because a lot of times there's no budget for monetary rewards. But the one thing that we really appreciate and look for is just somebody acknowledging and thanking us for what we did. A lot of [faculty members] go above and beyond the call of duty, and if those efforts are just ignored, faculty members might say [to themselves], "Why should I keep doing this? Nobody cares what I'm doing". And that's when I think people start going off in their own directions".

- Build on individual faculty members' strengths and minimise their weaknesses: Each faculty member has a unique set of strengths and weaknesses. Rather than one size fits all, it is better to consider how each person can contribute in ways that provide the most benefit to the department. "Take time to pay attention to what is going on, and try to be sensitive to how to approach people on their own level. Not everybody is going to be a star who hits the ball out of the park each time. You still need people on the team who can get the base hit or people who can play multiple positions even though they are not the star". Realising what people's strengths and weaknesses are and trying to maximise those strengths and minimise those weaknesses will be a positive move forward to not only building collegiality but also nurturing it. Individuals' strengths and interests can change over time, so it may be necessary to renegotiate expectations. Try to accommodate these individual faculty differences so that evaluation of teaching, scholarship and service are relevant to what each faculty member contributes to the department. "Often in the academic setting, we just expect everybody to excel in all three of those [realms], and it's just not realistic. I think some of the problems develop because there isn't a lot of flexibility in our system, and it's difficult for faculty members to excel at it all".

- Encourage cooperative work: Although not a formal departmental policy, faculty should be expected to spend at least $25 \%$ of their time in their scholarly activity working with someone else in the department. This goes for senior colleagues as well. "They're not just giving [junior colleagues] work to do - that never works. They are expected to be colleagues and help them by being an investigator on faculty member's project or to bring the new faculty member in and do handholding to make them see and realize how they would run a project". Having diverse disciplines within a single department helps foster interdisciplinary work. "I believe that the excitement happens at the margins. When two systems come together, the excitement - the dynamics - are at the margins where they connect" (Sorofman, 2011).

- Work closely with alumni, friends and advisory boards: Alumni are a valuable asset to a department, and they need to be kept abreast of what is happening in the department through visits, newsletters and annual reports. When alumni feel positively about the department, they want to give back, and then good things happen. If the department ignores its constituency and lacks communication with alumni, it will be much more difficult to get support to move the department forward. Because they are familiar with the department and yet are outside of it, advisory boards can provide valuable advice and insights. They can also help build endowments and address particular projects or goals. 
- Engage students: Current students are also a source of department vitality. Chan recommends using the student workforce to mutual advantage. An engaged student body is really the lifeblood of the department. We would not have a department without students. If you can figure out a way to mobilise and engage the students, that can help turn a department around. When the students are involved, they learn responsibility and feel that what they are doing is a contribution to the department. They feel invested in the department and its goals, and that can help move things forward.

- Look beyond the department: An outward future-oriented view - focusing on where a department and its impact on the community ought to be and how to get there - is crucial. Different components might include how to raise visibility, extend outreach, bring in more students and build community. Bringing in guest lecturers, alumni or others can provide new and different perspectives on research and teaching methods. Strong outside support from alumni and friends can help raise the stature of the department in the eyes of the administration. Collectively, all these points can help build a strong, healthy department that is vibrant and thriving. Moreover, these are hard and fast and identifiable in all situations, but they can be modified on case-to-case basis to suit the individual's and institutional requirements/needs.

Nevertheless, a positive work environment builds on itself and will perpetuate longlasting returns that will help ensure a solid departmental future.

- Measure success: It is important to measure the success of the departmental team. One way to measure success is by asking faculty about their job satisfaction and career going? If they are having a great career, then what is being done is something right. And in a department with collegiality, most of the faculty would say that they are having a great career. Other standard measures complete the picture: number of publications, grant funding, number of graduate students, graduate student placements and faculty awards.

- Align individual and department goals: Managing autonomous individuals often requires 'administrative judo', which can be defined as subtle redirecting colleagues (when necessary) to help align their goals with those of the department. For example, if a faculty member is excited about working on a certain grant that had little to do with his area. Rather than discourage this faculty member by saying, "You can't do that grant; It's got nothing to do with your area", it is better to gently point out to the faculty member in a more relevant direction by simply asking, "How can you make this more relevant to your area?" Another faculty member may want to do a certain kind of teaching that is interesting but not in alignment with the goals of the department. Rather than rejecting it out of hand, it is wise to ask, "How does it fit with the department's vision?"

- Keep up on the latest curricular changes in your discipline: Curriculum changes or differences of opinion about what should be taught and how it should be taught can create tension in any department. And the budget situation in many departments can add fuel to the fire. While there may be some overlap between approaches that provides common ground for faculty from different perspectives to collaborate, "there will be important differences past a certain point. Peer departments at other 
institutions, professional contacts, conferences and scholarly societies can provide useful information to help in making curricular decisions".

- Keep the big picture in mind: The real problem is not that so-and-so is a jerk. The real problem is that the department is way understaffed and everybody has too much work to do. Why? Because not enough money goes into public education. I think it helps a lot to look at the issue as a social problem instead of just a personality clash.

- Consider diverse opinions and do not let one person's opinion dominate: "I think if the department is well, there's room for everyone's opinion. Of course, if you're new there's a certain learning curve. On the other hand, sometimes when you're in the same job for many years, there's a tendency to get set in one's own ways. Some curriculum recommendations may come from outside the department". "There's a campaign in higher education to create a seamless transition from community college to four-year colleges or different schools in the same system by having some kind of common curriculum. So I think a lot of programs have been asked formally or informally to take a second look at their curriculum". "And there are going to be differences of opinion. Even before you discuss course A vs. course B, there are going to be differences of opinion as to the extent to which the department should take seriously these kinds of requests. Some people might say we should stand firm and not change anything". Other people will say, "No, we're going to have to change it anyway, so we might as well have some say in it". If a faculty member feels very strongly about a curricular issue, find out why it is so important to this person. Asking, why he/she feels so strongly about it is important and past a certain point, democracy wins. The majority wins and the minority loses.

\section{Implications}

In academics, knowledge exchange is an important component of research policies (Baporikar, 2014). The dissemination and use of knowledge is primarily through interactions with knowledge users (Ordóñez de Pablos and Tennyson, 2013). Companies and organisations are increasingly more aware of the importance of people and their knowledge for dealing with economic scenarios as complex as those we are seeing today, and of individuals with a capacity for long-term vision and leadership (Ordóñez de Pablos et al., 2015). However, knowledge is not only found in the individuals within companies and organisations but also in the relationships these individuals develop among themselves both inside and outside the company. There is also the knowledge present within the organisational structures and routines, in the company's policies, and in its organisational culture, among other areas (Ordóñez de Pablos and Tennyson, 2014); if this is true for organisations, then academic institutions also must realise that knowledge is not only found in the individuals within departments and faculty but also in the relationships these individuals develop among themselves both inside and outside the institution and the knowledge present within the structures and routines, in the academic policies and in its culture that can be fully utilised when there is an affable relationship and excellent collegiality.

In colleges and institutions, each faculty has undertaken advanced study in at least one discipline and has been trained in scholarly pursuits of knowledge. This common 
background results in an academic community in which faculty are roughly equally empowered members, a community in which 'authority is shared' (Weeks, 1996). This means that peer relations in the academy require more than civil working relationships; these relationships require the sharing of authority and decision-making in a way that is not common in many workplaces. These in no way means, in academics all have to always agree, but when they disagree, they need to do so productively. Unfortunately, that is frequently not the case.

\section{Conclusion}

What is collegiality in higher education today? Is it a nice idea or a nice frill? No. It is more like the glue that holds colleges and universities together to become universal platforms for knowledge exchange. Yet, incivility and toxic relationships within the academia are so common, that they are the number one reason while good teachers leave their positions or the worst is teaching excellence suffers. An academic community is not much different from society-at-large in that personalities and political agenda determine much of what is done and said. Bias and harassment based on gender, race, ethnicity or culture are evident in too many academic settings (Lumsden, 1997).

In its ideal state, however, the academy should be able to resolve these issues. The academic should be well prepared to participate (be active), examine issues (make observations), collaborate (work together), analyse alternatives (think critically) and synthesise new approaches (construct new knowledge). If this is how we want our students to solve problems, if it is what we hope to teach, then it is what we should model.

\section{References}

Ayers, W. (1993) To Teach: The Journey of a Teacher, Teachers College Press, New York.

Baporikar, N. (2013) '21st century higher education trends in Sultanate of Oman', in Ordóñez de Pablos, P. and Tennyson, R. (Eds.): Strategic Role of Tertiary Education and Technologies for Sustainable Competitive Advantage, Hershey, PA, pp.140-155, Information Science Reference, doi:10.4018/978-1-4666-4233-1.ch006.

Baporikar, N. (2014) 'Business research and new technologies', in Ordóñez de Pablos, P. and Tennyson, R. (Eds.): Strategic Approaches for Human Capital Management and Development in a Turbulent Economy, Hershey, PA, pp.166-192, Business Science Reference, doi:10.4018/978-1-4666-4530-1.ch011.

Buller, J.L. (2012a) The Essential Department Chair: A Comprehensive Desk Reference, Jossey-Bass, San Francisco.

Buller, J.L. (2012b) Best Practices in Faculty Evaluation: A Practical Guide for Academic Leaders, Jossey-Bass, San Francisco.

Cipriano, R. and Riccardi, R. (2013) 'A six year study of department chairs', The Department Chair, Summer, pp.22-24.

Cipriano, R.E. (2011) Facilitating a Collegial Department in Higher Education: Strategies for Success, Jossey-Bass, San Francisco.

Darling-Hammond, L. and McLaughlin, M. (1995) 'Policies that support professional development in an era of reform', Phi Delta Kappan, Vol. 76, pp.597-604. 
Deborah, L.H. and Helene, M.A. (2001) 'Collegiality and its role in teacher development: perspectives from veteran and novice teachers', Teacher Development: An International Journal of Teachers' Professional Development, Vol. 5, No. 3, pp.371-390.

Felps, W., Mitchell, T. and Byington, E. (2006) 'How, when, and why bad apples spoil the barrel: negative group members and dysfunctional groups', Research in Organizational Behavior, Vol. 27, pp.175-222.

Hargreaves, A. (1993) 'Individualism and Individuality: reinterpreting teacher culture', in Little, J.W. and McLaughlin, M. (Eds.): Teachers' Work: Individuals, Colleagues, and Contexts, Teachers College Press, New York.

Kelly, R. (2012) 'Six steps to a healthy department', Academic Leader, Vol. 28, No. 7, pp.1-6.

Little, J.W. (1990) 'The persistence of privacy: autonomy and initiative in teachers' professional relations', Teachers College Record, Vol. 91, pp.509-536.

Lumsden, A. (1997) Personal Communication, Florida State University.

McLaughlin, M. (1994) 'Strategic sites for teachers' professional development', in Grimmett, P. and Neufeld, J. (Eds.): Teacher Development and the Struggle for Authenticity: Professional Growth and Restructuring in the Context of Change, Teachers College Press, New York.

Ordóñez de Pablos, P. (2012) 'Knowledge in universities and research centres: proposed indicators for measuring relational capital', in Ordóñez de Pablos, P. and Lytras, M. (Eds.): Knowledge Management and Drivers of Innovation in Services Industries, IGI Global, Hershey, PA, pp.7-14, doi:10.4018/978-1-4666-0948-8.ch002.

Ordóñez de Pablos, P. and Tennyson, R.D. (2013) Strategic Role of Tertiary Education and Technologies for Sustainable Competitive Advantage, IGI Global, Hershey, PA, pp.1-369, doi:10.4018/978-1-4666-4233-1.

Ordóñez de Pablos, P. and Tennyson, R.D. (2014) Strategic Approaches for Human Capital Management and Development in a Turbulent Economy, IGI Global, Hershey, PA, pp.1-346, doi:10.4018/978-1-4666-4530-1.

Ordóñez de Pablos, P., Tennyson, R.B. and Zhao, J-Y. (Eds.) (2013) Intellectual Capital Strategy Management for Knowledge-Based Organizations, IGI Global, Hershey, PA, doi:10.4018/978-1-4666-3655-2.

Ordóñez de Pablos, P., Turró, L.J., Tennyson, R.D. and Zhao, J. (2015) Knowledge Management for Competitive Advantage During Economic Crisis, IGI Global, Hershey, PA, pp.1-364, doi:10.4018/978-1-4666-6457-9.

Sorofman B. (2011) 'Encouraging departmental teams', Academic Leader, Vol. 27, No. 10, pp.3-5.

Sutton, R.I. (2007) The No Asshole Rule: Building a Civilized Workforce and Surviving One That Isn't, Warner Business Books, New York.

Weeks, K.M (1996) 'Collegiality and the Quarrelsome Professor', Lex Collegii, Vol. 20, No. 1, College Legal Information, Nashville, Tennessee. 